\title{
Post-Harvest Losses and Control of Unprocessed Sugarcane
}

\author{
Mian Noor Hussain Asghar Ali, Liaquat Ali Jamali, Shakeel Ahmed Soomro*, Shakeel Hussain Chattha, \\ Khalil Ahmed Ibupoto, Naseer Ahmed Abbasi and Noor Mehdi Qumi
}

Sindh Agriculture University, Tandojam, Pakistan.

\begin{abstract}
Losses of quality parameters during sugar recovery process are of severe problems which are caused by delayed transportation with unfavorable storage conditions. Keeping the fact in view a study observing post-harvest losses of sugarcane was carried out at the Department of Farm Structures, Sindh Agriculture University, Tandojam. Freshly harvested SPF-234 sugarcane variety was collected and stored for 10 days under two different methods i.e. one kept open and other covered with sugarcane trash. The samples of sugarcane were taken at an interval of 24 hours to determine different quality parameters i.e. cane weight, brix, pol/sucrose, purity, fiber and commercial cane sugar. The results revealed that weight loss and fibre content throughout increased with increasing storage period. However, a decrease was observed with increasing storage period for brix content, sucrose content, purity percentage and commercial cane sugar percentage under both storage conditions. The observations of results further revealed that sugarcane covered with trash provided better quality (i.e. low weight loss, higher percentage of brix, sucrose percentage and commercial cane sugar) as compared to sugarcane kept open. From the outcomes of current study, it is strongly suggested that local farmers should adopt sugarcane trash cover method which do provides a convenient and safe storage system.

Received | December 06, 2017; Accepted | October 07, 2018; Published | November 05, 2018

*Correspondence | Shakeel Ahmed Soomro, Department of Farm Structures, Sindh Agriculture University, Tandojam, Pakistan; Email: shakeelsoomro@live.com

Citation | Hussain, M.N., L.A. Jamali, S.A. Soomro, S.H. Chattha, K.A. Ibupoto, N.A. Abbasi and N.M. Qumi. 2018. Post-Harvest losses and control of unprocessed sugarcane. Pakistan Journal of Agricultural Research, 31(4): 355-360.

DOI | http://dx.doi.org/10.17582/journal.pjar/2018/31.4.355.360

Keywords | Sugarcane, Storage period, Storage methods and Sugar loss.
\end{abstract}

\section{Introduction}

Sugarcane (Saccharum officinarum L.) is a cash crop of Pakistan and a source of livelihood for peoples of the country (Afghan et al., 2010). It dwells to the family Gramineae (Miller and Gilbert, 2010). Sugarcane acreage in $2014-15$ was at 1.141 million hectare which displayed a drop 2.7 percent against of last year with 1173 thousand hectares (GoP, 201415). Low sugarcane yield is of concern in many countries as being cash crop and export commodity it has strong influence on economy as a whole (Mahmood et al., 2016). As sugarcane is a perishable crop it is ought to be processed quickly as harvested. Delayed transportation with unfavorable environmental conditions causes loss of sucrose which is among the severe problems being observed during sugar recovery process. Studies have indicated that approximately 20-30\% of the total sucrose synthesized by sugarcane is lost during the various stages of raw material handling and processing. Delay in crushing has a loss of about 1.0 unit pol (percent cane) which has been argued by recent studies (Solomon et al, 2007). Loss of moisture and deficiency of physiological and biochemical control after harvested activates the endogenous invertases. Decay in commercial cane sugar in 
the harvested stored or stale cane has been observed with gentle growth in invertase(s) activity (Solomon et al., 1990). The post-harvest sugar loss is one of the alarming problems of sugar industry and has pulled in far-flung attention. Sugarcane isn't significantly in loss if crushed within 24 hours of harvest, but after 24 hours significant losses occur due to loss of moisture and low percentage of sucrose in juice (Solomon, 2009). The mechanical damages leading from the mechanical process comprises the most decisive element ascertaining the efficiency and profitability of a sugarcane harvester (Maleki and Almassi, 2010). Sugar loss is measured relative to a production system which would give a level best yield of sugar if the most adept conditions were provided (Ueno and Izumi, 1993).

Naturally, the composition of sugarcane alters from place to place as well it differs from variety to variety, the harvesting system and delay after harvesting for crushing leads to severe problem. Sugarcane Processing by-product compost supplemented with inorganic fertilizers application significantly affected the growth parameters of crop (Nawaz et al., 2016). Plant physiology is disrupted by cutting of sugarcane when harvested, these effects increases with increasing period between harvest and extraction of sucrose (Watt and Cramer, 2009). Increase in storage resulted significant decline of extractable sucrose percent in juice. A rapid increase in acidity and weight loss of sugarcane was also observed with increasing storage (Verma et al., 2012). The time lag between harvesting and processing generally outgoes 3-7 days which leads losses of recoverable sugar (Solomon et al., 2007). As small farmers due to lack of sufficient income cannot construct well developed structures to control the sugarcane losses being occurred. Thus, a proper, low cost and convenient method is necessary to be suggested, which could lead to maintain the quality parameters of harvested sugarcane until its processing. Keeping the above facts in view, the current study was designed to assess the losses of harvested sugarcane under different storage methods and to suggest a proper and convenient method.

\section{Materials and Methods}

The present study was carried out at the Department of Farm Structures, Faculty of Agricultural Engineering, Sindh Agriculture University Tandojam. Freshly harvested sugarcane (SPF-234 variety) was collected from Rashdi Agricultural Farm, Tando Allahyar.
Sugarcane was divided into two lots and stored for 10 days under different storage methods i.e. one kept open while other was covered with sugarcane trash. The samples of sugarcane were taken at an interval of 24 hours to assess the following quality parameters,

\section{Cane weight loss}

The cane weight was recorded with the help of digital weighing balance at harvesting time. The weight loss percentage was recorded using the following formula:

$$
\text { weight loss }(\%)=\frac{\text { Initial weight }- \text { Weight after storage }}{\text { Initial weight }} \times 100 \ldots .(1)
$$

\section{Brix content}

Total solids content present in juice is referred as Brix, which is expressed in percentage. Brix in juice was recorded with brix hydrometers.

\section{Sucrose percentage}

It is the real percentage of cane sugar present in juice. Polari-meterwasused during test.Equation mentioned below was used for calculating sucrose percentage.

Sucrose $\%=$ Reading of Polari meter $\times 0.752$ for $200 \mathrm{~mm}$ (tube factor) ....... (2)

\section{Purity percentage}

It is considered as maturity of the crop for harvesting. The purity percentage was calculated with the help of the following formula (Yadava, 1993).

$$
\text { Purity }(\%)=\frac{\text { Sucrose }}{\text { Brix }} \times 100
$$

\section{Fibre percentage}

The fibre is the dry dusty pulp that remains after juice is extracted fromsugarcane.Formulagivenbelowwasused for reckoning fibre percentage, Chen and Chou (1993).

Moisture percentage in bagasse $=\frac{\text { Loss in weight }}{\text { weight sample }} \times 100$

Iuice percentage of bagasse $=\frac{\text { Mositre percentage of bagasse }}{1-\text { Juice brix } \div 100} \times 100 \ldots \ldots(5)$

Fiber percentage bagasse $=100-$ Juice percentage of bagasse $\ldots . . .(6)$

Fiber percentage cane $=\frac{\text { Bagasse } \% \text { cane } \times \text { Fiber } \% \text { bagasse }}{100} \times 100 \ldots \ldots .(7)$ 
Commercial cane sugar (percentage)

The commercial cane sugar (CCS) refers to the total recoverable sugar percent in the cane, which was calculated using following formula, Meade and Chen (1997).

$\operatorname{CCS}=\frac{3 \times S}{2}\left(1-\frac{F+5}{100}\right)-\frac{B}{2}\left(1-\frac{F+3}{100}\right) \ldots \ldots$

Furthermore, average temperature, humidity, wind velocity and sun shine hours were recorded during the experiment. Statistix Software (ver. 8.1) was used for analysis of variance (ANOVA).

\section{Results and Discussion}

Significant losses occurred were observed even within 24 hours of staling whereas losses gradually increased with increase in storage time (Figure 1). A maximum loss of 27.8 and $15.7 \%$ after 10 days of storage was observed respectively for sugarcane kept open and covered with trash. Statistical analysis of variance showed significant $(p<0.05)$ effect of storage period and methods. Moisture vaporization after being harvested is the cause of weight loss for sugarcane. The results are in line with Srivastava et al. (2009), who reported that the effective method to minimize sugar and cane weight in stale sugarcane is with covering the harvested cane.

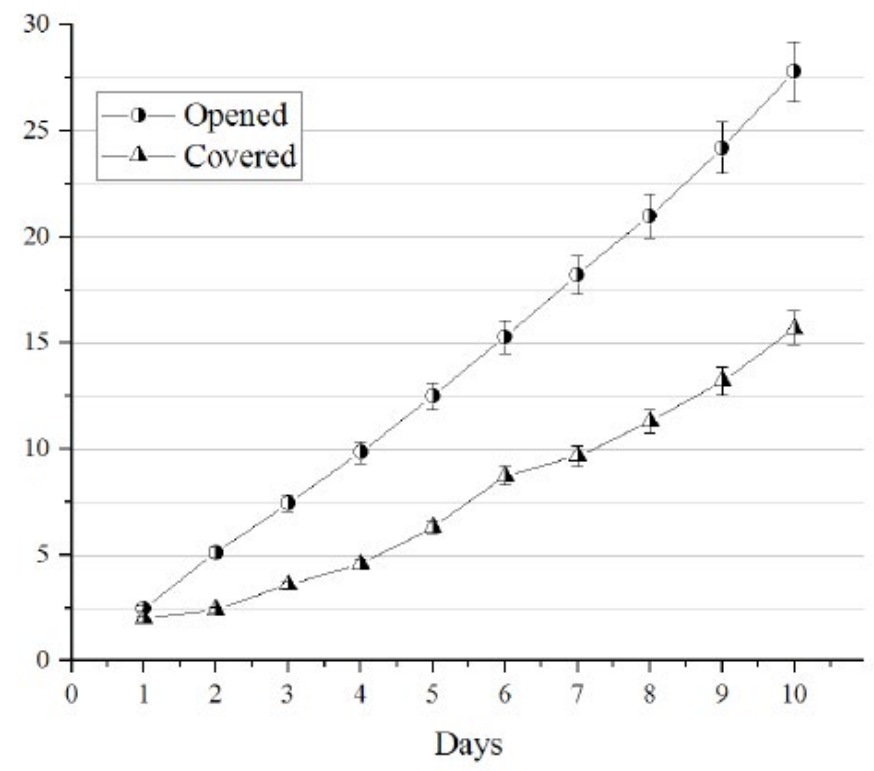

Figure 1: Average weight loss (\%)

Analysis of variance (ANOVA) indicated a significant $(p<0.05)$ effect of storage period and methods on brix percentage (Figure 2). Brix percentage decreased gradually with the passage of storage time. Initial brix percentage in sugarcane was observed to be $19.26 \%$ which then decreased to $15.83 \%$ and $17.15 \%$ for sugarcanes kept open and covered with sugarcane trash. Brix percentage directly relates to moisture deficit in cane, which decreases with a decrease in weight loss. The results are in line with Briket and Stein (2004) who reported that brix content is adversely affected by delay in processing of cut cane.

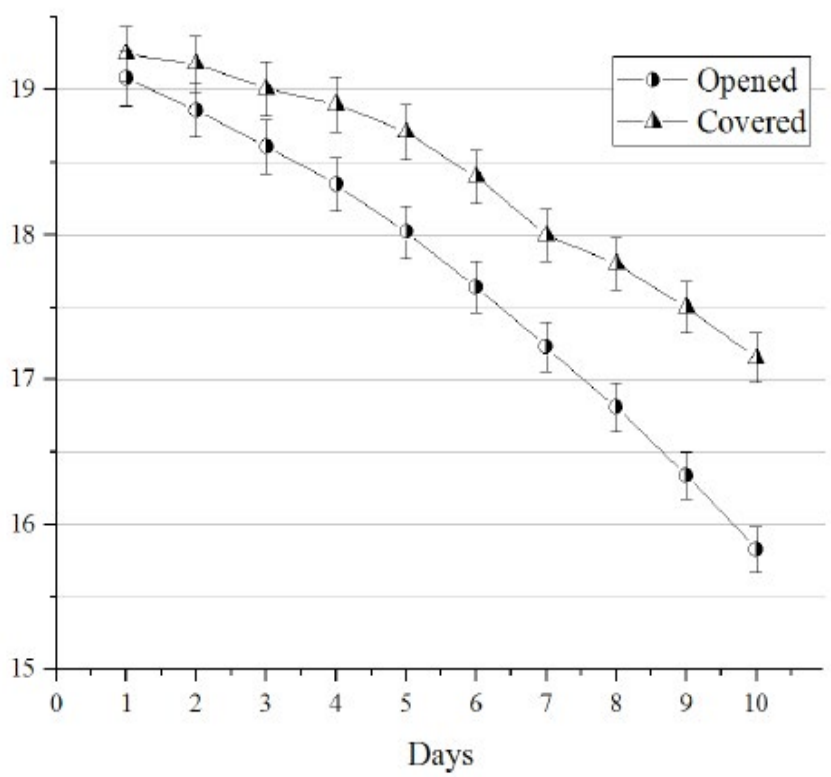

Figure 2: Average brix percentage.

The graphical representation shown in Figure 3 shows the losses occurred in pol/sucrose of sugarcane for both applied conditions. Sucrose percentage of sugarcane was significantly $(\mathrm{p}<0.05)$ affected by storage period and methods. Initial sucrose percentage was observed to be 15.90 which then decreased to $10.87 \%$ and $12.97 \%$ respectively for sugarcane kept open and covered with trash. The loss in pol/sucrose might be due to the aging of harvested cane via continuing inversion and their biochemical and microbiological agents. The results are in line with Rakkiyappan et al. (2009) who reported that each day delay in processing of harvested cane decrease pol/sucrose in cane.

A gradient increase in loss of purity percentage after harvesting was observed in both conditions applied (Figure 4). The analysis of variance showed that the storage period and methods had significant $(\mathrm{P}<0.05)$ affect. Percentage of purity decreased with increase in period of storage, maximum loss of 68.73 and $78.70 \%$ were observed respectively for methods kept open and covered with trash. The loss of purity is subjected to harvesting time and temperature, increasing storage and higher temperature lead more loss for the canes kept open. The results are in line with Sohu et al. 
(2011), they founded adverse effect on purity percentage of juice in cane with each day delayed after harvest.

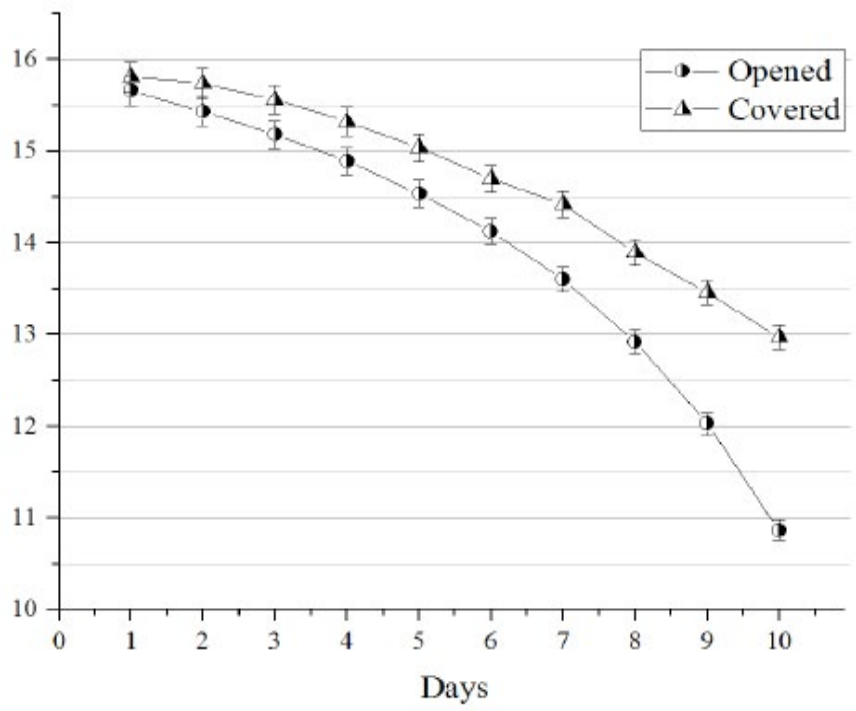

Figure 3: Average sucrose percentage.

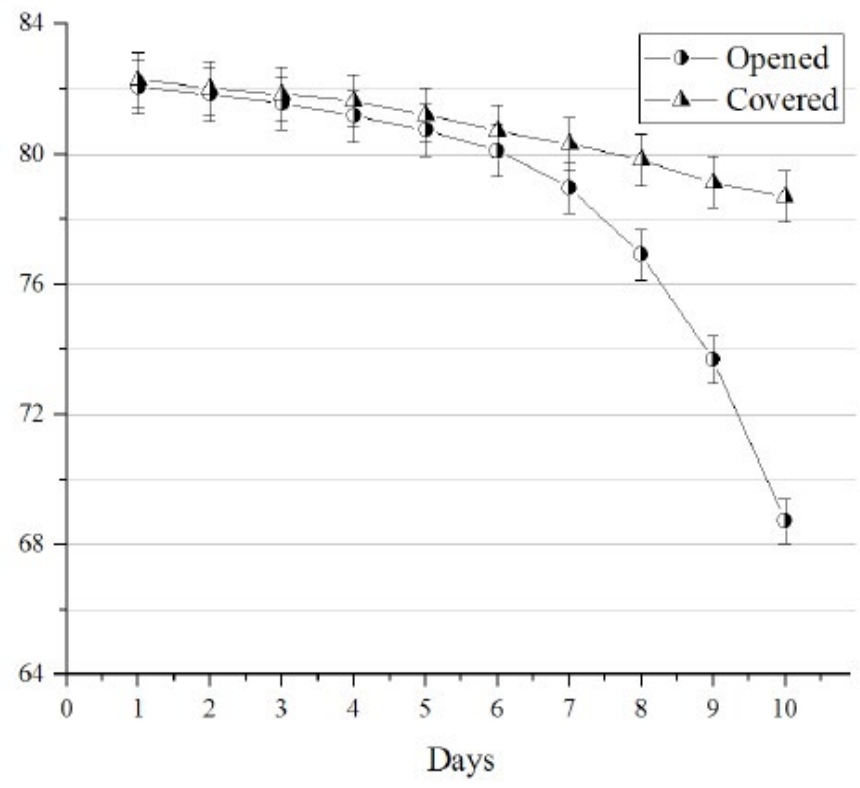

Figure 4: Average purity percentage.

Losses for Fibre percentage occurred in canes are graphically shown in Figure 5. Fibre percent of cane increased with increasing the number of days. The study resulted that the fibre percentage in sugarcane kept open increased from 15.70 to 19.18 whereas for sugarcanes covered with trash resulted an increase in loss from 15.70 to 17.46 . The analysis of variance showed a significant $(p<0.05)$ effect of storage period and methods. This may be due to the environmental temperature, possibly breaking down the insoluble polysaccharides. The results are in line with Nazir et al. (2000) and Sohu, et al. (2011) they reported that there was an inverse effect on fibre content in cane and it consecutively increased with each delayed day.
Affected percentage of commercial cane sugar (CCS) for both conditions are shown in Figure 6. Initial observation for sugarcane was observed to be 11.08 while after 10 days the percentage reduced to 6.51 and 8.25 respectively for sugarcane kept open and covered with trash. The analysis of variance showed that the storage period and methods had significant $(\mathrm{p}<0.05)$ affect. This refers to the total recoverable sugar percent in the cane, which with passage of period and loss of moisture decreases, greater loss of CSS was observed for the canes which were kept open. The results are in line with Uppal and Sharma (2004), who's consolidated experience, revealed that each day delay in milling of harvesting cane would result substantial loss of commercial cane sugar (CCS).

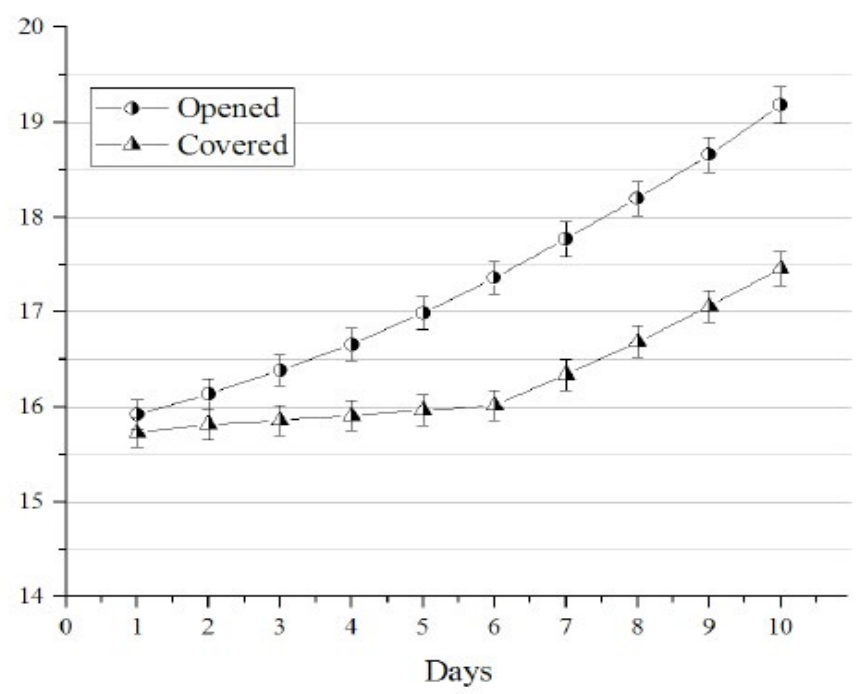

Figure 5: Average fibre percentage.

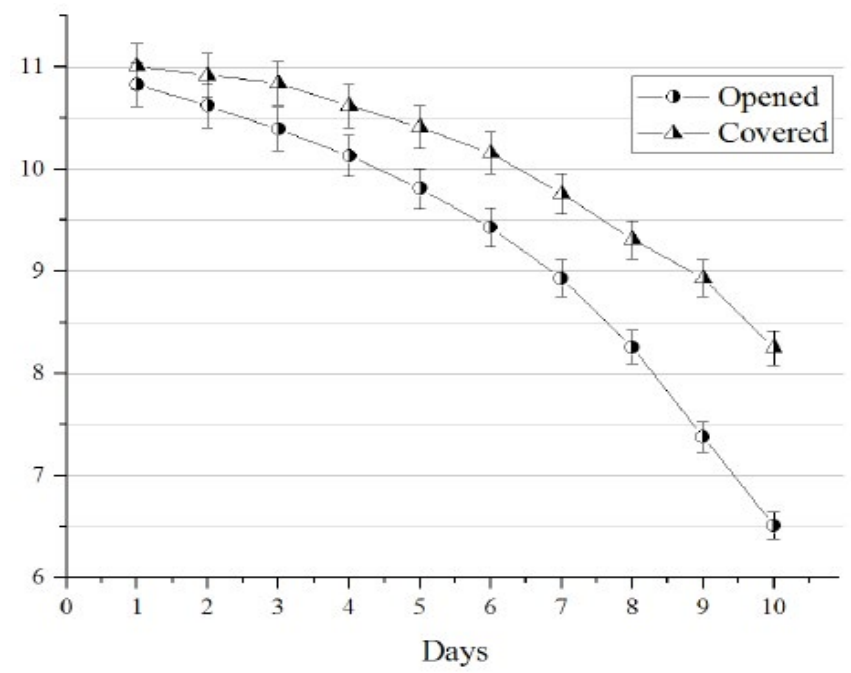

Figure 6: Average commercial cane sugar (CCS) percentage.

\section{Conclusions}

Method of preserving sugarcane with trash proved that the sugarcane can be preserved at a very low cost 
with minimum quality losses until sold. As it does not require any expertise or advance technology, it is strongly suggested to the farmers to adopt the method covered with trash for storing, which do provides a convenient and safe storage system.

\section{Author's Contribution}

Mian Noor Hussain AA and Liaquat Ali Jamali conceived the idea; Mian Noor Hussain AA, Naseer Ahmed Abbasi and Noor Mehdi Qumi collected the data; Khalil Ahmed Ibupoto and Shakeel Hussain Chattha helped in developing the methodology section and reviewed final manuscript; Mian Noor Hussain AA and Shakeel Ahmed Soomro analysed the data and wrote the paper.

\section{References}

Afghan, S., Hussnain, Z., Hussain, K., Shahazad, A. and Ali, K. 2010. Comparison of quantitative and qualitative traits of sugarcane (Saccharum officinarum L.) diverse genotypes. Pak. Sugar J. XXV (1): 12-15.

Birkett, H.S. and Stein J.M. 2004. Cane storage losses - Part 1. Sugar J. 67 (4): 17-21.

Chen, J.C.P. and Chou C.C. 1993. Chen-Chou cane sugar handbook: a manual for cane sugar manufacturers and their chemists /by James C.P. Chen, Chung-Chi Chou. 12thEd. New York: J. Wiley. XXV: 1090.

GOP. 2015. Economic Survey of Pakistan, 201415. Ministry of Finance, Economics Advisory wing, GoP, Islamabad.

Mahmood,I.,Hassan, S., Yasin, M.R., Bashir,A. and Abbas,M.2016. Determinants of sugarcane yield differentials across selected districts of central Punjab: An Empirical Investigation.J. Agric. Res. 54 (2): 331-341.

Maleki, M.G. and Almassi, M. 2010. Determination of Cane Billets Quality Standard in Mechanical Harvesting of Sugar Cane. The 5th National Conference on Agr. Machinery Eng. and Mechanization, Ferdowsi Univ. Meshed, Iran. Issue Paper: 281.

Meade, C.P. and Chen, J.C.P. 1977. Cane sugar hand book, 10th edition. John Wiley and sons, Inc. New York. pp, 01-947.

Miller, J.D. and Gilbert R.A. 2010. Sugarcane Botany: A Brief View. IFAS-University of Florida, FL, USA.
Nawaz, M., M. U. Chattha, M. B. Chattha, H. Munir and R. Ahmad 2016. Sugarcane processing by-product compost supplemented with inorganic fertilizers improve the growth, yield quality of spring planted sugarcane (Saccharum Officinarum L.). J. Agric. Res. 54 (4): 631-645.

Nazir, M.S., Jamil, K., Jabbar, A. and Nawaz, S. 2000. Differential genotypic performance of autumn planted sugarcane. Pak. Sugar J. 15 (2): 8-11.

Rakkiyappan, P., Shekinah, D.E. Gopalasundaram, P., Mathew M.D. and Asokan S. 2009. Post-harvest deterioration of sugarcane with special reference to quality loss. J. Sugar Tech. 11 (2): 167-170. https://doi.org/10.1007/ s12355-009-0025-5

Sohu, I.A., Sarki, M.S. and Abro B. 2011. Determination of Post-Harvest Deterioration in Upcoming Sugarcane Varieties. Pak. Sugar J. 26 (2): 10-17.

Solomon, S. 2009. Post-harvest deterioration of sugarcane. Sugar Tech. 11(2): 109-123. https:// doi.org/10.1007/s12355-009-0018-4

Solomon, S, Shrivastava A.K. and Yadav. R.L 2007. Strategies to minimize post-harvest surcrose losses in sugarcane. An overview Proc. Ann. Conv. STAI 68:112 - 121.

Solomon, S., Srivastava A.K., Bhatnagar, S. and Madan V.K. 1990. Post-harvest changes in invertase activity and juice quality in sugarcane. India. Sugar. 39 (12): 895-899.

Srivastava, R.P., Siddhant and Sharma, M.L. 2009. Studies on minimizing quality and quantity losses in stale cane. J. Sugar Tech. 11 (2): 176180. https://doi.org/10.1007/s12355-0090027-3

Ueno, M. and Izumi, H. 1993. Sugar Loss due to Mechanic al Harvesting. Int. Sugar. J. nl. 95(1131E): 75-78.

Uppal, S.K. and Sharma, S., 2004. Post-harvest losses in sugarcane under different weather conditions. India. Sugar J. 3 (1/2): 209-213.

Verma, A.K., Singh, S.B., Arun, K., Agarwal and Solomon, S. 2012. Influence of postharvest storage temperature, time, and invertase enzyme activity on sucrose and weight loss in sugarcane. Post-harvest Bio. Technol. Volume 73, Pages 14-21.

Watt, D.A. and Cramer, M.D. 2009. Post-harvest biology of sugarcane. Mini Review, Sugar Tech. 2 (2): 142-145. https://doi.org/10.1007/ 

ciples and practice. Lucknow, U.P., India: Int. Book Distributing Co., Publ. Div. 